\title{
Avaliação do docente pelo discente na melhoria do desempenho institucional: UTFPR/SIAVI
}

\author{
Miraldo Matuichuk* \\ Maclovia Corrêa da Silva**
}

\section{Resumo}

Este artigo apresenta aspectos da avaliação institucional como parte das atividades da educação superior. Trata-se de importante estratégia para a gestão institucional liderada, no Brasil, pelo Ministério da Educação (MEC). A Comissão Nacional de Avaliação da Educação Superior coordena o Sistema Nacional de Avaliação da Educação Superior - SINAES - o qual trabalha com três grandes universos: a avaliação das instituições, dos cursos e do desempenho dos estudantes. A finalidade desta estratégia baseia-se na responsabilidade social, na qualidade da educação superior, no reconhecimento da diversidade do sistema, no respeito à identidade, e na missão educacional histórica das instituições. A Universidade Tecnológica Federal do Paraná - UTFPR - tem uma Comissão Própria de Avaliação, vinculada ao SINAES que promove, dentre outras avaliações, a do docente pelo discente. 0 presente estudo visa a analisar a organização da primeira plataforma do Sistema de Avaliação Institucional - SIAVI do docente, implantada em 2009, e suas interações com os princípios dos modelos avaliativos de caráter participativo (resolução de problemas), colaborativo (evolução constante), e emancipativo (cidadania e inclusão), visando a introduzir propostas de melhorias.

Palavras-chave: Avaliação na Educação Superior.UTFPR/SIAVI. Discente. Avaliação docente.

\section{Evaluation of teachers by students in the improvement of institutional performance: UTFPR/SIAVI \\ Abstract}

This paper presents the institutional evaluation as part of the activities of higher education. It is an important strategy for institutional management in the country led by the Ministry of Education (MEC). The National Evaluation of Higher Education coordinates the National System of Higher Education - SINAES - working with

* Mestre em engenharia da produção e doutor em educação pela UDELMAR - professor da Universidade Tecnológica Federal do Paraná.E-mail: miraldo@utfpr.edu.br

** Doutora em estruturas ambientais urbanas - professora do Programa de Pós-Graduação em Tecnologia da Universidade Tecnológica Federal do Paraná. E-mail: macloviasilva@utfpr.edu.br 
three major universes: the evaluation of schools, courses and student performance. The purpose of this strategy is based on social responsibility, quality of higher education, recognition of the diversity of the system in regard to identity and the historical mission of educational institutions. Federal Technological University of Paraná - UTFPR - has an evaluation committee, linked to SINAES that promotes, among other measures, the student evaluation for the teacher's activities. The present study aims to analyze the organization of the first platform of the teacher's Institutional Assessment System - SIAVI, established in 2009, and their interactions with the principles of the participatory nature of models of evaluation (problem solving), collaboration (evolution) and emancipation (citizenship and inclusion), with the aim of introducing proposals for improvement.

Keywords: Higher education evaluation. UTFPR/SIAVI. Student. Teacher evaluation.

\section{Evaluación del docente por parte del discente en la mejora del desempeño institucional: UTFPR/SIAVI Resumen}

Este artículo presenta los aspectos de la evaluación institucional como parte de las actividades de la educación superior. Ésta es una estrategia importante para la gestión institucional en el país dirigido por el Ministerio de Educación (MEC). La Comisión Nacional de Evaluación de la Educación Superior coordina el Sistema Nacional de Evaluación de la Educación Superior - SINAES - que trabaja con tres universos principales: la evaluación de las instituciones, de los cursos y del desempeño de los estudiantes. El propósito de esta estrategia se basa en la responsabilidad social, calidad de la educación superior, en reconocimiento de la diversidad del sistema, en lo que se refiere a la identidad y la misión histórica de las instituciones educativas. La Universidad Tecnológica Federal de Paraná - UTFPR - cuenta con una Comisión Propia de evaluación, vinculada al SINAES que promueve, entre otras evaluaciones, la del profesor por parte del estudiante. El presente estudio tiene como objetivo analizar la organización de la primera plataforma del Sistema de Evaluación Institucional - SIAVI del profesor, establecida en 2009, y sus interacciones con los principios de carácter participativo de modelos de evaluación (resolución de problemas), colaboración (en constante evolución), y de emancipación (ciudadanía e inclusión), con el objeto de introducir propuestas de mejora.

Palabras-clave: Evaluación de la Educación Superior. UTFPR/SIAVI. Discente. Evaluación docente.

\section{Introdução}

Os procedimentos de avaliação do processo de ensino-aprendizagem na Universidade Tecnológica Federal do Paraná UTFPR estão inseridos em contexto de avaliação nacional da Educação Superior liderado pelo Ministério da Educação MEC e pelo Instituto Nacional de Estudos e Pesquisas Educacionais Anísio Teixeira 
- INEP. Esta autarquia federal auxilia o MEC na implantação de políticas públicas na área educacional, e produz informações para educadores e outros públicos. Em especial, o INEP analisa os dados e informações coletados nas Instituições de Ensino Superior e verifica a realidade destes espaços escolares (INEP, 2010).

A avaliação das instituições de educação superior, nas modalidades de autoavaliação coordenada por uma comissão própria de cada instituição, e da avaliação externa realizada por comissões indicadas pelo INEP, faz parte do Sistema Nacional de Avaliação da Educação Superior (SINAES). Este sistema avalia os aspectos institucionais, inclusive o corpo docente, no que se refere ao ensino, à pesquisa e à extensão a fim de traçar um perfil das instituições e da qualidade de seus cursos. O INEP, ao operacionalizar os processos, define os membros da Comissão Nacional de Avaliação da Educação Superior (CONAES) para coordenar e estabelecer as diretrizes de avaliação . Lê-se na portaria do MEC n.․ 2.051, de 09 de julho de 2004:

Parágrafo único. A realização da avaliação das instituições, dos cursos e do desempenho dos estudantes será responsabilidade do INEP, o qual instituirá Comissão Assessora de Avaliação Institucional e Comissões Assessoras de Áreas para as diferentes áreas do conhecimento. (BRASIL, 2004).

A avaliação institucional será o referencial básico para o processo de credenciamento e recredenciamento das instituições, com os prazos de validade estabelecidos pelos órgãos de regulação do Ministério da Educação. Um aspecto da avaliação institucional é a vertente da autoavaliação, a qual é coordenada pela Comissão Própria de Avaliação CPA. No contexto deste artigo, estuda-se um dos instrumentos da CPA da UTFPR - Campus Curitiba - para os cursos de graduação, que é a avaliação do docente pelo discente, uma vez que existe uma estreita relação entre avaliação e formação, visando à qualidade das ações acadêmicas e administrativas dos cursos. Segundo a lei de 2004,

Art. 2ㅇ 0 SINAES, ao promover a avaliação de instituições, de cursos e de desempenho dos estudantes, deverá assegurar:

I - avaliação institucional, interna e externa, contemplando a análise global e integrada das dimensões, estruturas, relações, compromisso social, atividades, finalidades e responsabilidades sociais das instituições de educação superior e de seus cursos; II - o caráter público de todos os procedimentos, dados e resultados dos processos avaliativos;

III - o respeito à identidade eà diversidade de instituiçõese de cursos; IV - a participação do corpo discente, docente e técnico administrativo das instituições de educação superior, e da sociedade civil, por meio de suas representações. (BRASIL, 2004). 
No conjunto, os processos avaliativos integram as diversas dimensões da realidade a ser avaliada. A instituição de ensino superior oferece um ambiente social de ensino-aprendizagem para o campo da educação, e a avaliação do desempenho dos docentes é um mecanismo importante de informações que faz a diferença na busca constante da melhoria da qualidade do ensino.

0 instrumento analisado neste trabalho é aplicado em dois momentos no ano letivo. Hoje, a avaliação é feita em formulários eletrônicos e sofreu uma reformulação, aqui analisada, entre os anos de 2008 e 2009.0 acesso é feito via internet e intranet na UTFPR durante um período pré-agendado e os departamentos fazem a divulgação (UTFPR, 20094). Este processo de participação efetiva dos alunos tem como objetivo a melhoria de práticas didático-pedagógicas e a construção do conhecimento. No Campus Curitiba, realizouse em 2009 o processo de avaliação docente pelo discente com os alunos regularmente matriculados nos cursos do Ensino Superior, Educação Técnica Profissional, e Educação Jovens e Adultos. Foi organizada uma subcomissão constituída por um representante de cada Departamento Acadêmico do Campus para ajudar no processo de sensibilização e acompanhamento, buscando coletar amostras significativas dos dados (ADPD, 2009).

A Avaliação Institucional divide-se em duas modalidades: a autoavaliação - Coordenada pela Comissão Própria de Avaliação (CPA) de cada instituição e orientada pelas diretrizes e pelo roteiro da autoavaliação institucional da CONAES; e a avaliação externa, realizada por comissões designadas pelo INEP, que tem como referência os padrões de qualidade para a educação superior expressos nos instrumentos de avaliação e os relatórios das autoavaliações. 0 processo de avaliação externa independe de sua abordagem e tem uma visão multidimensional que busca integrar sua natureza formativa e de regulação numa perspectiva de globalidade.

Em seu conjunto, os processos avaliativos devem constituir um sistema que permita a integração das diversas dimensões da realidade avaliada, assegurando as coerências conceitual, epistemológica e prática, bem como o alcance dos objetivos dos diversos instrumentos e modalidades. Para gerar seus dados e estudos educacionais o INEP realiza levantamentos estatísticos e avaliativos em todos os níveis e modalidades de ensino.

\section{Antecedentes históricos}

No presente estudo o objetivo é analisar a organização da primeira plataforma do Sistema de Avaliação Institucional - SIAVI do docente, implantada em 2009 na UTFPR, e suas interações com os princípios de modelos avaliativos de caráter participativo (resolução de problemas), colaborativo (evolução constante), e emancipativo (cidadania e inclusão), visando a introduzir propostas de melhorias. Segundo Ibarrola,

${ }^{4}$ Portaria n. 0567 de 18 de maio de 2009. 
Uma melhor cultura da avaliação permitirá apreciar os alcances, os limites e os efeitos das avaliações e o lugar que Ihes corresponde dentro da melhora da educação. Permitirá distinguir entre uma verdadeira transformação curricular e 0 abuso do término da "reforma" como proposta política reiterada [...] (IBARROLA, 2008, p. 2).

A questão da Avaliação Institucional nas universidades brasileiras foi discutida pelo movimento docente e, a partir de 1982, começou um amplo debate coordenado pela Asso ciação Nacional dos Docentes do Ensino Superior (ANDES). Em 1986, a Universidade de Braślia - UNB iniciou o projeto de avaliação institucional, apresentando um documento que marcou a trajetória desse processo no sentido de fornecer subsídios para a tomada de decisões nos níveis individual e coletivo da instituição. Destacou-se a participação da comunidade acadêmica na busca de ela alcançar objetivos e cumprir com suas finalidades científicas e sociais da avaliação. Esta proposta de avaliação institucional inseriu 0 instrumento de avaliação do ensino nos níveis de graduação e de pós-graduação.

Dos trabalhos resultantes desta experiência, foi criada a Comissão Nacional de Avaliação da Educação Superior, em 1993, que institucionalizou um programa pela Coordenadoria Geral de Análise e Avaliação Institucional da Secretaria da Educação Superior - SESu - e um Programa de Avaliação Institucional das Universidades Brasileiras - PAIUB. Em 2001, o processo avaliativo sofreu mudanças com a revogação dos Decretos 2.026 de 1996 e 2.306 de 1997, que regulamentavam a avaliação e a organização da educação superior (BRASIL, 1996). Passou a vigorar o Decreto n-3.860, de 9 de julho de 2001, 0 qual dispunha sobre a classificação das instituições de ensino superior, entidades mantenedoras, organização acadêmica, avaliação e procedimentos operacionais. Coube ao Ministério da Educação coordenar a avaliação dos cursos (INEP), programas e instituições credenciando ou descredenciando instituições.

A Comissão Especial de Avaliação - CEA - foi designada pelas Portarias do governo federal MEC/SESu, n. -11 , de 28 de abril de 2003 e $n-19$, de 27 de maio de 2003, sendo oficialmente instalada pelo Ministro da Educação, Cristóvam Buarque, em 29 de abril de 2003. A referida comissão foi criada com a finalidade de "analisar, oferecer subsídios, fazer recomendações, propor critérios e estratégias para a reformulação dos processos e políticas da Educação superior e elaborar a revisão crítica dos seus instrumentos, metodologias e critérios utilizados" (SINAES, 2003).

Presidida pelo professor José Dias Sobrinho, que coordenou os trabalhos com reuniões quinzenais nas capitais brasileiras: Brasília, Curitiba, Porto Alegre, Rio de Janeiro e Recife. Estas medidas oportunizaram momentos de produtivas discussões com entidades representativas da sociedade, em especial aquelas ligadas à educação superior, e foram apresentadas contribuições, e propostas de reformulação do sistema avaliativo brasileiro. 
Desde 2004, o Sistema Nacional de Avaliação da Educação Superior tem promovido 0 aprofundamento de compromissos e responsabilidades sociais das instituições de educação superior, por meio da valorização da missão pública, da promoção dos valores democráticos, do respeito à diferença e à diversidade, da afirmação da autonomia e da identidade institucional. Os princípios avaliativos consubstanciados pelo SINAES procuram contemplar a complexidade do ensino superior brasileiro, articulando as dimensões do processo de ensino, aprendizagem, capacidade institucional e responsabilidade social da instituição (BRASIL, 2004).

Concepções de avaliação como processo responsável pela qualidade na formação de ensino superior nos contextos nacional e internacional deram origem às qualidades do SINAES: um sistema autônomo, emancipatório, regulador e comprometido com a educação. Enquanto sistema de avaliação das instituições de educação superior IES - dos cursos de graduação e o desempenho dos estudantes, busca cumprir suas finalidades, dentre as quais a de manter a continuidade de um processo avaliativo fortalecedor dos propósitos da educação. Baseia-se em princípios fundamentados nas noções de globalidade, isto é, a compreensão de que a instituição deve ser avaliada por um conjunto significativo de indicadores de qualidade, vistos em sua relação orgânica e não de forma isolada.

\section{Procedimentos metodológicos}

Esta pesquisa faz uso dos recursos de análise qualitativa de práticas inovadoras de coleta de dados de um instrumento institucional de investigação avaliativa. Este foi concebido a partir de um trabalho coletivo e interdisciplinar, em consonância com a missão e com as políticas institucionais. A proposta de discussão conta com 0 apoio teórico de autores como Stufflebeam, Shinkfield, Ibarrola, e Vargas.

A UTFPR conta com a Comissão de Avaliação Permanente do Docente pelo Discente responsável pela coordenação do processo. Ela é composta por dois representantes da Pró-reitoria de Graduação; um representante de cada campus da UTFPR; um representante do Núcleo de Apoio Psicopedagógico e Apoio ao Estudante (NUAPE); um representante da Assessoria de Tecnologia da Informação AINFO), e um aluno convidado.

A análise do instrumento de avaliação de 2009 da UTFPR - plataforma do Sistema de Avaliação Institucional - SIAVI - é singular, uma vez que ele inova sua plataforma em relação ao ano de 2008. As categorias de agrupamento mudaram e o número de questões diminuiu. Hoje, o discente tem acesso a um instrumento de caráter participativo, colaborativo e emancipativo. 0 mesmo contém perguntas pertinentes à organização didático-pedagógica, ao corpo docente, corpo discente, corpo técnico-administrativo e instalações físicas institucionais. 
Para mostrar a evolução citam-se algumas diferenças entre os processos avaliativos: em 2008 o processo de compilação dos dados era parcialmente informatizado, os resultados eram aproximados, havia 15 perguntas fechadas e uma questão aberta; em 2009, as novidades introduzidas ampliaram o campo dos resultados com a avaliação por professor e por turma (colaborativa), a identificação do professor, a redução de erros com a segurança dos resultados (emancipativa), a recuperação automática de senhas, e a redução do número de questões sem perder a objetividade das informações (participativo).

A avaliação do docente pelo discente compõe-se de duas fases distintas, sendo a primeira, a fase de aplicação do processo, e a segunda, a fase de acompanhamento pedagógico do professor pelo Departamento de Educação. A primeira fase tem início com a sensibilização dos Coordenadores dos Cursos e dos Chefes dos Departamentos Acadêmicos em reunião com o representante da Comissão do Campus visando à participação do discente. A sensibilização também conta com a divulgação na página eletrônica da UTFPR. A segunda fase tem início após a finalização do processo de avaliação, contando com apoio do Núcleo de Apoio Psicopedagógico e Apoio ao Estudante - NUAPE, no assessoramento aos Chefes de Departamento Acadêmico e Coordenadores de Curso, e no acompanhamento pedagógico de docentes (ver Figura 1).

Figura 1 - Fluxo do processo de avaliação do docente pelo discente.

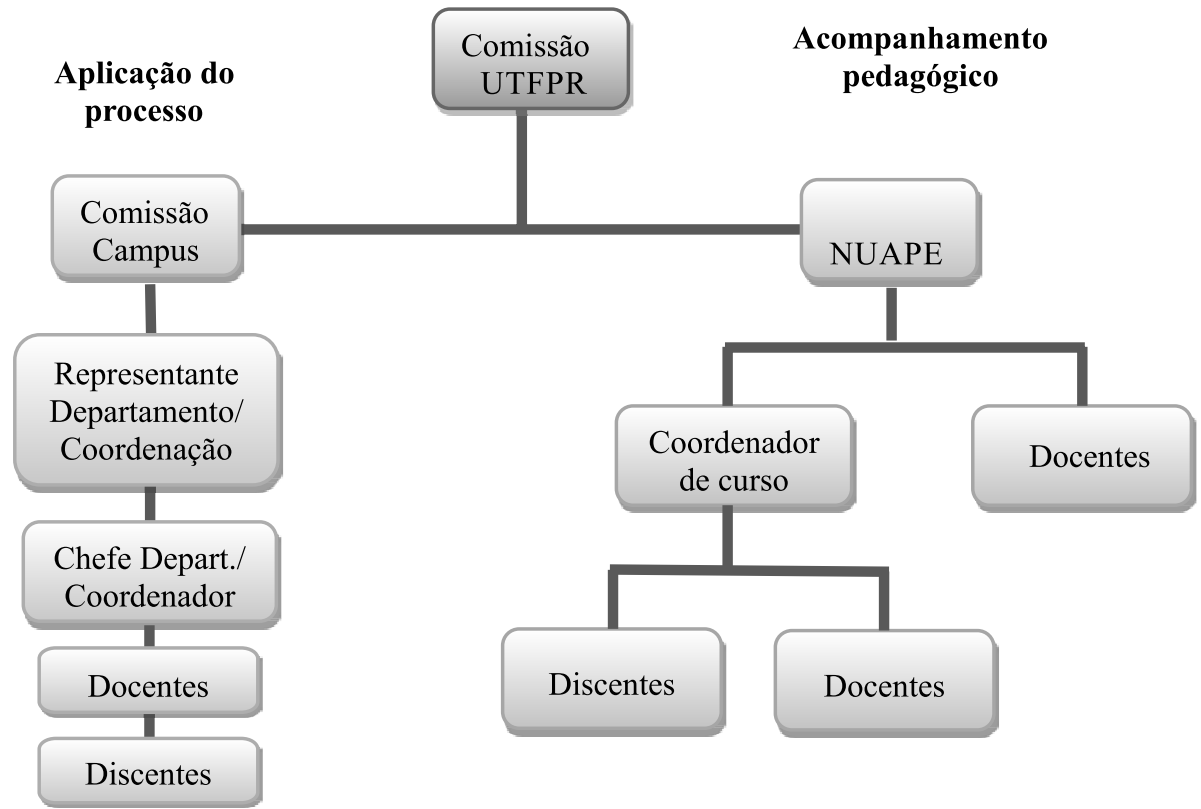

Fonte: CADPD, (2009). 


\section{Abordagens teóricas}

Na perspectiva da aplicação da avaliação na gestão da melhora da instituição, a avaliação se constitui em estratégia na tomada de decisões que orientem a gestão institucional. Leis, regulamentos, decretos e circulares podem exercer uma força para identificar os pontos fortes e fracos da avaliação. Stufflebeam explica que a "avaliação [...] é o processo de identificar e coletar informações que permitem decidir entre várias alternativas" (STUFFLEBEAM et al. (1971) apud VIANNA, 1989, p. 21).

Stufflebeam (1983) liderou um grupo de profissionais desejosos de organizar um programa virtual de avaliação sistêmica que colaborasse com os levantamentos de necessidades institucionais e suas consequentes melhorias. A avaliação institucional das Instituições de Ensino Superior - IES - constitui importante estratégia de gestão na busca da qualidade de ensino, pesquisa e extensão. Contudo, requer conhecimento analítico e crítico da realidade interna e externa das trajetórias educacionais. Este advém da organização do processo de avaliação institucional. "O grau de conhecimento institucional se relaciona à sua capacidade de conhecer-se, de avaliar-se" (EYNG, 2004).

A avaliação institucional pode configurar-se nas seguintes etapas:

a) Recolher informações que reflitam, o mais fielmente possível, a situação inicial da situação a avaliar.

b) Elaborar juízos de mérito ou valor a partir de critérios previamente estabelecidos ou consensuados no contexto do próprio processo da avaliação.

c) Tomar decisões de melhora que conduzam à eleição e aplicação de alternativas de intervenção mais adequadas a partir da informação avaliada ou em processo avaliativo.

A avaliação do docente pelo discente é realizada pelos alunos ingressantes e concluintes dos cursos avaliados, que fazem uma prova de formação geral e formação específica. As avaliações feitas pelas comissões de avaliadores designadas pelo INEP caracterizam-se pela visita in loco aos cursos e instituições públicas e privadas e se destinam a verificar as condições de ensino, em especial aquelas relativas ao perfil do corpo docente, às instalações físicas e à organização didático-pedagógica.

0 processo de avaliação requer o estabelecimento dos organizadores prévios, o conhecimento já existente e a integração desses com as novas informações num processo que interagem as informações advindas da avaliação. Partindo das informações do conhecimento já sistematizados integram a esses as informações advindas dos procedimentos de autoavaliação, respectivamente, avaliação interna e avaliação externa.

$\mathrm{Na}$ autoavaliação devem participar os membros da comunidade educativa tais como: estudantes, autoridades acadêmicas, 
pessoal administrativo e de apoio técnico entre outras participações de interesse para o projeto. Deve conceber-se como uma avaliação integral que analisa profundamente o plano ou programa de estudos em suas distintas etapas: planejamento, execução e administração, além do mais permite delinear um plano de trabalho para realizar as modificações que sejam necessárias (VARGAS, 2010, p. 21).

A relação dos dados provenientes da avaliação interna e externa, os quais são analisados neste texto que se refere às diferentes contribuições dos teóricos da avaliação educacional e da sua aplicação no âmbito da avaliação institucional. Bertelli (2004, p. 38), indica que:

Os estudos da avaliação institucional iniciados por Tyler na década de 40, até os dias atuais receberam inúmeras contribuições. Dentre essas, destacam-se nesse estudo as contribuições de Cronbach (1963), Scrivem (1967), Stake (1967), Stufflebeam (1971), Provus (1971), Worthen e Sanders, (1973), Popham, (1975), Belloni (2000), Dias Sobrinho (1995, 1997, 2000, 2002a, 2002b, 2003a, 2003b).

A avaliação com caráter participativo, um instrumento científico e ético, Prieto (2009) coloca alunos, professores, pesquisadores e membros de comissões em um cenário comunitário que traz transformações para o processo ensino-aprendizagem, ajuda na tomada de decisões, e pode ser usado como suporte para estabelecimento de políticas. Reflete também nas ações sociais dos usuários e dos gestores responsáveis pela aprendizagem institucional (valorização, poder, habilidades).

Segundo Vargas, todo processo de avaliação institucional tem com requisito e condição indispensável a participação da comunidade educativa. Isto quer dizer que a avaliação realizada somente por agentes externos à vida institucional tende a fracassar, pois não contempla o processo participativo. Limitando sua participação mediante a aplicação de um instrumento de perguntas fechadas, não abrange 0 currículo, a administração, a infraestrutura, os equipamentos e o planejamento.

En los procesos realizados por las carreras se evidencian procesos participativos que involucran docentes, estudiantes, autoridades académicas y entes empleadores, especialmente. Se señalan las fortalezas y las estrategias para la solución de las debilidades. Sin duda, que estas acciones y otras que surgen como producto de la autoevaluación, marcan la diferencia en la calidad de la educación (VARGAS, 2010, p. 24).

0 instrumento de avaliação com perguntas fechadas pode também ser participativo quando os níveis de participação das pessoas envolvidas são 
predefinidos. É importante que elas estejam integradas ao processo e às tomadas de decisões. Nesse sentido, o processo social, político e educativo precisa ser reflexivo a ponto de provocar mudanças de atitudes para melhorar a qualidade de ensino e recriar as regras básicas da avaliação. A facilitação de informações, a ética, 0 compromisso com os resultados incrementam a prática avaliativa, o crescimento cognitivo e o desenvolvimento pessoal dos participantes.

Os aspectos colaborativos da avaliação também são fundamentais para a tomada de decisões e resoluções de problemas. Isto implica uma abrangência da colaboração para todas as etapas dos programas implementados nas instituições. 0 avaliador tem uma posição estratégica na coordenação das atividades, da escolha de pessoal, e dos aspectos técnicos do processo. As comissões são compostas de variadas representações nas atividades de elaboração e interpretação das informações valorizando a utilidade da avaliação enquanto técnicas e metodologias. Segundo Prieto $(2009$, p. 8) "A principal pergunta é em que se diferenciam os enfoques de avaliação participativa de outras formas de avaliação colaborativa e das investigações também colaborativas. Em geral as diferenças são de matizes".

Stufflebeam e Shinkfield (1995) dizem que os organizadores de estudos políticos, considerando as diretrizes federais para a melhoria do Ensino Superior, precisam priorizar a igualdade de oportunidades, dando resposta à sociedade, no sentido de contribuir para uma cultura avaliativa emancipativa. A consolidação destes atos se dá com a socialização dos dados coletados durante os processos avaliativos ea valorização participativa integral dos envolvidos nas práticas, nas discussões e interpretações dos dados.

Segundo a Declaração dos Direitos Humanos, toda pessoa tem direito ao acesso à educação superior em plena igualdade. Na Constituição Brasileira de 1988, 0 direito à educação é um direito social:

Art. 60 São direitos sociais a educação, a saúde, a alimentação, o trabalho, a moradia, o lazer, a segurança, a previdência social, a proteção à maternidade e à infância, a assistência aos desamparados, na forma desta Constituição (BRASIL, 1988).

As atitudes inovadoras criam um capital social que se volta para a emancipação da sociedade em favor da capacitação permanente de pessoas e comunidades. Programas educacionais flexíveis, baseados em parcerias, com avaliações constantes, permitem chegar à conquista da emancipação de pessoas e comunidades.

\section{Análise da avaliação do docente pelo discente}

Durante 0 período em que ocorre a avaliação do docente pelo discente, prevista em calendário acadêmico, 0 aluno pode acessar 0 site http://aluno.utfpr.edu.br, e 
selecionando o Campus, entrar com sua senha pessoal e, depois de aceita a identificação, o aluno pode interagir com a plataforma do Sistema de Avaliação Institucional - SIAVI - para avaliar seus professores.

0 aluno poderá acessar 0 site Institucional do aluno para realizar sua matrícula, conferir seu boletim escolar, confirmar matricula, obter seu histórico escolar e poder avaliar os professores com os quais ele teve aulas durante o semestre letivo (ver Figura 2).

Figura 2 - Portal de acesso acadêmico do aluno.

\begin{tabular}{|c|c|c|}
\hline \multicolumn{3}{|c|}{ Pinistério da Educação } \\
\hline & Iuno Online ${ }_{\text {http://aluno.utfpredu.br }}$ & www.utfpr.edu.br UГГPR \\
\hline Apucarana & \multirow{4}{*}{\multicolumn{2}{|c|}{$\begin{array}{l}\text { Este sistema é compativel com os navegadores: } \\
\text { - Firefox } 1.5 \text { (portugues Brasil) (necessita configurar o SSL2); } \\
\text { - Internet explorer 6; }\end{array}$}} \\
\hline Campo Mourão & & \\
\hline Cornélio Procópio & & \\
\hline Instruçöes matrícula & & \\
\hline Curitiba & \multirow{8}{*}{\multicolumn{2}{|c|}{$\begin{array}{l}\text { Para acessar o sistema, clique no campus da UTFPR ao qual está vinculado. } \\
\text { Aqui você poderá: }\end{array}$}} \\
\hline .Instruçöes matrícula & & \\
\hline Dois Vizinhos & & \\
\hline Francisco Beltrẫo & & \\
\hline Londrina & & \\
\hline Medianeira & & \\
\hline Pato Branco & & \\
\hline Ponta Grossa & & \\
\hline Instruçöes matrícula & \multirow{4}{*}{\multicolumn{2}{|c|}{$\begin{array}{l}\text { Para acessar o sistema é necessário o uso de senha pessoal. } \\
\text { Caso ainda não a possua, ou se a esqueceu, retire-a na secretaria. } \\
\text { LEMBRE-SE: sua senha é de uso pessoal. Tudo o que for feito com o uso dela é de } \\
\text { sua inteira responsabilidade. }\end{array}$}} \\
\hline Toledo & & \\
\hline $\mathrm{FAQ}$ & & \\
\hline Recuperar Senha & & \\
\hline
\end{tabular}

Fonte: UTFPR, (2009).

Ao selecionar a "realizar a avaliação de seu (s) professor (es)", aparece a tela da plataforma do Sistema de Avaliação Institucional - SIAVI com informações e recomendações iniciais de preenchimento e apresenta a escala de conceitos que podem ser atribuídos para avaliar cada professor. (ver Figura 3). 
Figura 3 - Tela apresentada ao discente para as recomendações de preenchimento.

\section{Recomendações de preenchimento}

Caro aluno,

Neste momento solicita-se sua participação para auxiliar na avaliação de desempenho dos docentes por entender-se que ela é indispensável para a melhoria contínua das atividades desenvolvidas em sala de aula.

Para tanto, é necessário que sua opinião não se baseie em impressões precipitadas ou ditadas pela emoção. Procure avaliar o professor nos quesitos propostos, baseando sua resposta no que é mais constante no comportamento do professor.

\begin{tabular}{|c|c|}
\hline \multicolumn{2}{|c|}{ Escala de conceitos } \\
\hline Nunca & 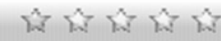 \\
\hline Raramente & 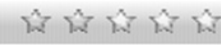 \\
\hline Algumas Vezes & 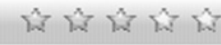 \\
\hline Quase Sempre & 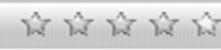 \\
\hline Sempre & 金食食食食 \\
\hline
\end{tabular}

\section{Continuar}

Fonte: UTFPR, (2009).

$\mathrm{Na}$ avaliação do docente pelo discente da UTFPR estão propostas cinco perguntas que abrangem os aspectos de didática, conteúdo, planejamento, avaliação e relacionamento. Além da tela que contém as perguntas, existe uma tela auxiliar com a descrição explicativa das categorias individualizadas.

A pergunta para avaliar a didática do professor [o professor apresenta o conteúdo de forma clara e objetiva?] refere-se à forma de apresentação dos conteúdos programáticos das disciplinas e suas relações com os aspectos profissionais e sociais. Dois adjetivos de grande amplitude, "clara e objetiva", devem ser graduados na escala de conceitos (nunca, raramente, algumas vezes, quase sempre, sempre), conforme apresentado na Figura 3.

Vale lembrar que os alunos são os mais interessados em estabelecer as relações entre disciplinas e profissões deles, desejando frequentar somente disciplinas que venham a agregar conhecimento às suas formações. Então, este item é bastante interessante para o aluno porque ele implica atendimento ou não de suas expectativas de aquisição de conhecimento. 0 nome das disciplinas e os conteúdos são itens decisivos para 0 aluno no momento da matrícula, na frequência às aulas e na forma de avaliação.

Depois de lidas as recomendações e avançando à tela seguinte, 0 aluno passa a conhecer em quais as categorias e com que indicadores ele poderá avaliar cada um de seus professores. (ver Figura 4). 
Figura 4 - Tela explicativa de categorias e indicadores avaliativos.

\begin{tabular}{|c|c|}
\hline \multicolumn{2}{|r|}{ Descrição das Categorias e indicadores } \\
\hline \multirow[t]{2}{*}{ Conteúdo } & $\begin{array}{l}\text { Refere-se ao conhecimento demonstrado pelo Professor sobre os Conteúdos } \\
\text { Programáticos da Disciplina, bem como, ao relacionamento que o Professor } \\
\text { estabelece entre estes Conteúdos Programáticos e aspectos profissionais y } \\
\text { sociais. }\end{array}$ \\
\hline & O professor demonstra conhecimento a respeito do conteúdo? \\
\hline \multirow[t]{2}{*}{ Didática } & $\begin{array}{l}\text { Refere-se ao comportamento do Professor em sala de aula enquanto agente } \\
\text { promotor do ensino-aprendizagem, sua maneira de agir, os recursos e as } \\
\text { técnicas que utiliza para facilitar o aprendizado, motivar e despertar o } \\
\text { interesse sobre os temas tratados. }\end{array}$ \\
\hline & O professor apresenta o conteúdo de forma clara e objetiva? \\
\hline \multirow[t]{2}{*}{ Planejamento } & $\begin{array}{l}\text { Refere-se ao cumprimento e distribuição dos Conteúdos Programáticos ao } \\
\text { longo do desenvolvimento da Disciplina. Deve-se levar em conta se o } \\
\text { Professor apresenta previamente um planejamento do semestre e cumpre o } \\
\text { estabelecido inicialmente. }\end{array}$ \\
\hline & O professor apresenta as ações a serem realizadas durante o período letivo? \\
\hline \multirow[t]{2}{*}{ Avaliaçẫo } & $\begin{array}{l}\text { Refere-se ao estabelecimento da forma de avaliação, da quantidade e } \\
\text { critérios de avaliação. Deve-se levar em conta, também, se o Professor } \\
\text { cumpre aquilo que estabeleceu previamente em sala de aula no início do } \\
\text { semestre letivo. }\end{array}$ \\
\hline & O professor estabelece previamente os parâmetros da avaliação? \\
\hline \multirow{2}{*}{\begin{tabular}{|l|} 
Relacionamento \\
\end{tabular}} & $\begin{array}{l}\text { Refere-se à forma como o Professor se relaciona com os alunos dentro e fora } \\
\text { da sala de aula. Deve-se, também, avaliar se Professor manteve o controle } \\
\text { de classe durante o semestre priorizando o bom desenvolvimento da } \\
\text { disciplina. }\end{array}$ \\
\hline & O professor mantém postura adequada à prática do ensino? \\
\hline \multicolumn{2}{|r|}{ Comentários dos Alunos } \\
\hline \multicolumn{2}{|c|}{1 ozxquyysjjccsgjkovsf } \\
\hline \multicolumn{2}{|c|}{2 pjjifnwnbmrkblxtxgkq } \\
\hline
\end{tabular}

Fonte: UTFPR, (2009).

Após avaliar as categorias, 0 aluno tem um campo destinado para dar sugestões e realizar os comentários que julgar necessários, a Figura 5 apresenta um exemplo de preenchimento deste campo.

Figura 5 - Tela de comentários.

\section{Comentários dos Alunos (todos)}

Assim como outros professores, sugiro que nao fassam a selecao de alunos,como por exemplo

selecionando uma panelınha da sala e achando que todos os alunos tem que ser iguais a

1 esses. Isso é descriminacao com o potencial dos outros alunos. Todos devem participar e nao

sempre os mesmos.

Um educador excelente, inteligente, de admirável conhecimento sobre o conteúdo do curso, que nos

ensina de maneira capaz e ótima!

O professor em questão deveria trabalhar mais o seu relacionamento com os alunos, procurando

tratar a todos de maneira igual.

4 O melhor professor que eu já tive dentro da insttuição. sem mais!

Fonte: UTFPR, (2009).

Todavia, a avaliação da didática fica bastante restrita à ação da apresentação dos conteúdos e aos recursos e técnicas de aprendizagem. 0 objetivo da didática

Ensaio: aval. pol. públ. Educ., Rio de Janeiro, v. 21, n. 79, p. 323-348, abr./jun. 2013 
é o ensino pelo docente capacitado e nele podem estar implicados os conteúdos e a maneira de expô- los.

Nota-se que começa a ruir a idéia de uma didática como conjunto de técnicas e saberes metodológicos indispensáveis à arte de ensinar algo a alguém. Percebe-se também o início de um novo sentido, de um novo olhar, implicando a necessidade de alargamento do horizonte que orienta o processo ensinaraprender e de percepção da presença de um conjunto mais amplo de interesses e interessados na educação (SANTOS, 2003, p. 138).

Na verdade, a didática é mais abrangente do que as técnicas e do que o saber fazer, pois trabalha com conceitos de identidade entre o professor e a disciplina, entre a reflexão sobre os conteúdos e a teoria, e a interdisciplinaridade que permite uma fecunda relação entre as disciplinas. Vale dizer que o professor pode concentrar- se no simples cumprimento do programa sem se preocupar com a aprendizagem do aluno.

Quanto aos conteúdos das disciplinas [o professor demonstra conhecimento a respeito do conteúdo?] e das escolhas de dividi-los em partes teóricas e práticas, estes podem ser repassados de formas diversificadas, atreladas aos potenciais didáticos dos professores e das áreas de conhecimento a que se dedicam. Muitos professores da Instituição possuem formações acadêmicas e vivências empresariais que permitem a singularidade na organização dos conteúdos de suas disciplinas. É importante que os alunos da UTFPR saibam que esta instituição se caracteriza pela produção de tecnologia, pela presença da multidisciplinaridade na organização das disciplinas, afastando-se das universidades clássicas existentes no país.

Uma forma bastante atual é a educação a distância. 0 professor pode mesclar suas aulas entre presenciais e virtuais. Ele certamente precisa dominar o conteúdo e adquirir práticas que venham a produzir conhecimento. As tecnologias são veículos para criar espaços virtuais de aprendizagem significativa e interação entre 0 aluno e o professor.

Uma formação reflexiva implica que o professor em sua própria prática pedagógica seja crítico em relação aos conteúdos disponibilizados e construa novos conteúdos ao longo de sua formação. É um processo que demanda tempo, e principalmente envolvimento do professor nas discussões, sobre o uso dos recursos midiáticos na educação escolar (MORAES; TERUYA, [2010], p. 9).

Outro aspecto importante da avaliação do docente pelo discente é o planejamento [o professor apresenta as ações a serem realizadas durante o período letivo?] dos conteúdos programáticos. É a terceira pergunta da avaliação do docente 
pelo discente que está centrada nos conteúdos. Cabe ao aluno avaliar a prévia apresentação dos conteúdos a serem desenvolvidos, o cronograma das aulas e 0 cumprimento do mesmo pelo professor.

No século XXI, com uma enxurrada de informações disponíveis nos meios midiáticos, as disciplinas perderam seu rumo estável e os campos disciplinares estão em constante mutação. Este "fenômeno" faz da ferramenta de planejamento um meio de dar novos sentidos aos contextos de mutação em que vivemos. Ele guia a execução das propostas de conteúdos e funciona como diretriz para equilibrar as atividades de ensino, pesquisa e extensão.

\begin{abstract}
Quando se fala em planejamento na área da educação, ouvese falar nos seguintes termos: planejamento educacional, planejamento escolar, planejamento de ensino, planejamento curricular. Mas afinal, todos estes termos não são relacionados à educação propriamente dita? Existem diferenças entre esses termos? E antes disso, 0 que os estudiosos falam sobre o termo planejamento? Quais as finalidades pedagógicas de um planejamento de ensino? Por que o professor deve planejar? Qual é a sua importância para o processo de ensinoaprendizagem? (KLOSOUSKI; REALI, 2008, p. 2).
\end{abstract}

Planejar é uma estratégia que ajuda o professor a pensar sobre o que faz e sobre sua responsabilidade em formar cidadãos, profissionais preparados para a vida e para o trabalho. Saber o que é mais importante dentre os conteúdos, na relação ensino aprendizado, não é suficiente se o planejamento de ensino estiver ausente. É tão importante estabelecer objetivos, quanto procurar alcançá-los. As políticas públicas podem cooperar nesse processo, estabelecendo regras e cursos para melhorar o desempenho do educador no planejamento do cotidiano de suas práticas pedagógicas.

A quarta pergunta a que o discente responde na avaliação do docente trata da organização da avaliação dos conteúdos programáticos pelo professor [o professor estabelece previamente os parâmetros da avaliação?]. Ela faz parte de todo 0 processo educativo e implica um julgamento de valor sobre o professor, o que ele está fazendo e sobre os resultados de seu trabalho. Para possibilitar a introdução de melhorias na qualidade de ensino, a avaliação precisa ser descentralizada das ações de desenvolvimento cognitivo.

Percebemos que Piaget tem um posicionamento contrário diante desta avaliação que exclui 0 indivíduo, pois esta não examina de fato toda aprendizagem, 0 desenvolvimento do aluno, mesmo que não seja o desejável ou ao nível do currículo de determinada série, também podemos afirmar que este 
defende a avaliação que considera o cotidiano escolar, as relações que os alunos estabelecem e seu desenvolvimento individual (MARTN, 2007).

A produção de conhecimento, de ensino, de aprendizagem, de pesquisa são práticas educativas que transcendem a simples transmissão e avaliação de conhecimentos. Por isso, o processo de avaliação, quando mobilizador de práticas cotidianas para criar condições de aprendizagem, trabalha com o significado do desenvolvimento integral do aluno - social e pessoal.

A avaliação retrata o momento de o professor e de o aluno refletirem sobrea construção dos saberes e conhecimentos. Se ela estiver centrada no intelecto, na transmissão de conteúdos, ela incorpora dificuldades de superação do mecanicismo de assimilação e transmissão de conteúdos. Os resultados, quando vinculados ao ensino e aprendizado, permitem a redefinição dos rumos das ações pedagógicas dos docentes e encaminham as práticas de transformação de atitudes e metodologias. Ela tem função pedagógica, didática, diagnóstica e de controle para o professor promover a aprendizagem.

Na última pergunta da avaliação do docente pelo discente da UTFPR está presente a categoria "relacionamento" - [0 professor mantém postura adequada à prática do ensino?]. Avalia-se a forma como o professor se relaciona com os alunos na sala de aula e nos ambientes externos da instituição e como este agir repercute 0 desenvolvimento da disciplina. A interação e a aprendizagem acontecem quando os princípios do respeito são validados por ambas as partes. Os exercícios do diálogo entre as pessoas que pensam, agem e têm sentimentos podem transformar as práticas educativas e os relacionamentos. Cabe ao professor, que é o líder da sala de aula "favorecer a aquisição do saber a partir do diálogo, pois é através deste que os sujeitos se encontram no verdadeiro momento de aprendizagem, diluindo-se as hierarquias" (VASCONCELOS et al. 2005, p. 2).

As instituições de ensino são socializadoras no sentido da convivência em grupo. No ambiente de respeito torna-se possível 0 desenvolvimento afetivo e a criação de significados entre professores e alunos. Além disso, é um espaço de apropriação do conhecimento na dimensão profissionalizante em que a educação intelectual, o comportamento e a afetividade direcionam as ações.

As interações professor-aluno desempenham um importante papel e mais do que pautadas pelas ações que um dirige ao outro, são afetadas pelas representações mútuas, ou seja, pelas idéias que um tem do outro; assim, estas interações não podem ser reduzidas ao processo cognitivo de construção do conhecimento, pois envolvem dimensões af etivas e motivacionais (VASCONCELOS et al. 2005, p.9). 


\section{Análise da avaliação do docente pelo discente}

Neste item, após a leitura crítico-reflexiva sobre as perguntas e os textos complementares que compõem a tela de avaliação do docente pelo discente, passamos a expor como ocorre o processo para o aluno no espaço virtual. Ao entrar na página da Universidade Tecnológica Federal do Paraná, o discente acessa o portal do aluno e encontra as telas anteriormente expostas nas Figuras 1, 2, 3 e 4.

Após a leitura e as recomendações, 0 aluno poderá seguir o processo acessando a tela de avaliação que informa se há "pendências" (falta avaliar) e as ocorrências já "realizadas" (estão avaliadas). As avaliações podem ser feitas na medida em que 0 aluno considerar relevante fazê- lo. Pode também, mas não necessariamente, avaliar todos os seus professores de uma só vez. Porém, esse processo não tem reversão e não há possibilidade de alterações depois de finalizado. A Figura 6 ilustra a tela que 0 aluno acessa para escolher as disciplinas em que ele está matriculado, os códigos correspondentes, e os nomes dos respectivos professores.

Figura 6 - Tela de disciplinas e professores para ser avaliado pelo aluno.

\begin{tabular}{|c|c|c|c|c|c|}
\hline$\theta \geqslant$ & \multicolumn{5}{|c|}{$\begin{array}{c}\text { Avaliação do Docente pelo Discente } \\
1^{0} \text { semestre/2009 }\end{array}$} \\
\hline & \multicolumn{5}{|c|}{ Aluno: $\quad 000000 \cdots$ Nononor } \\
\hline \multirow{13}{*}{ Avaliaçõe } & Ação & Código & \multicolumn{2}{|l|}{ Disciplina } & Professor \\
\hline & Avaliar & $\mathrm{CCO} 6 \mathrm{D}$ & \multicolumn{2}{|c|}{ Gestão Do Meio Ambiente } & Stella Maris Da Cruz Bezerra \\
\hline & Avaliar & CCO6E & \multicolumn{2}{|c|}{ Resistência Dos Materiais 2} & Ricardo Karvat \\
\hline & Avaliar & $\mathrm{CCO} F \mathrm{~F}$ & \multicolumn{2}{|c|}{ Instalações Hidráulicas 1} & Fernando Jose Matitz \\
\hline & Avaliar & CE06A & \multicolumn{2}{|l|}{ Lingua Portuguesa 6} & Sindia Rosa Ballen Da Silva \\
\hline & Avaliar & CLO6A & \multicolumn{2}{|l|}{ Inglês 4} & Marcia Regina Becker \\
\hline & Avaliar & ESO6A & \multicolumn{2}{|l|}{ História 6} & Rafael Augustus Sega \\
\hline & Avaliar & ESO6B & \multicolumn{2}{|l|}{ Filosofia 2} & Valter Cardoso Da Silva \\
\hline & Avaliar & FI06A & \multicolumn{2}{|l|}{ Física 6} & Joao Angelo Pucci Tosin \\
\hline & Avaliar & FI06A & \multicolumn{2}{|l|}{ Física 6} & Talmi Bohn Silva \\
\hline & Avaliar & MA06A & \multicolumn{2}{|l|}{ Matemática 6} & Paulo Agostinho Alessio \\
\hline & Avaliar & QB06A & \multicolumn{2}{|l|}{ Química 6} & Sonia Zanello \\
\hline & Avaliar & QB06B & \multicolumn{2}{|l|}{ Biologia 6} & Marco Antonio Coelho \\
\hline \multicolumn{6}{|c|}{ Avaliações Realizadas } \\
\hline & \multicolumn{3}{|c|}{ Código Disciplina } & \multicolumn{2}{|c|}{ Professor } \\
\hline & \multicolumn{2}{|c|}{ CCO6G } & Ensaios Tecnológicos & \multicolumn{2}{|c|}{ Jose Carivaldo Brandao Junior } \\
\hline & \multicolumn{2}{|c|}{ ESO6C } & Geografia 4 & \multicolumn{2}{|c|}{ Paulo Alexandre Maluf } \\
\hline
\end{tabular}

Fonte: UTFPR, (2009).

Para cada avaliação, há necessidade de selecionar o código, a disciplina e 0 professor, identificado também com a imagem pessoal, responder às perguntas 
seguindo a escala de conceitos para cada tema - didática, conteúdo, planejamento, avaliação relacionamento - e tecer comentários, caso ele deseje complementar as idéias do questionário, abordar assuntos não tocados na avaliação, ou colocar sugestões. (ver Figura 7).

Figura 7 - Tela de avaliação do docente.

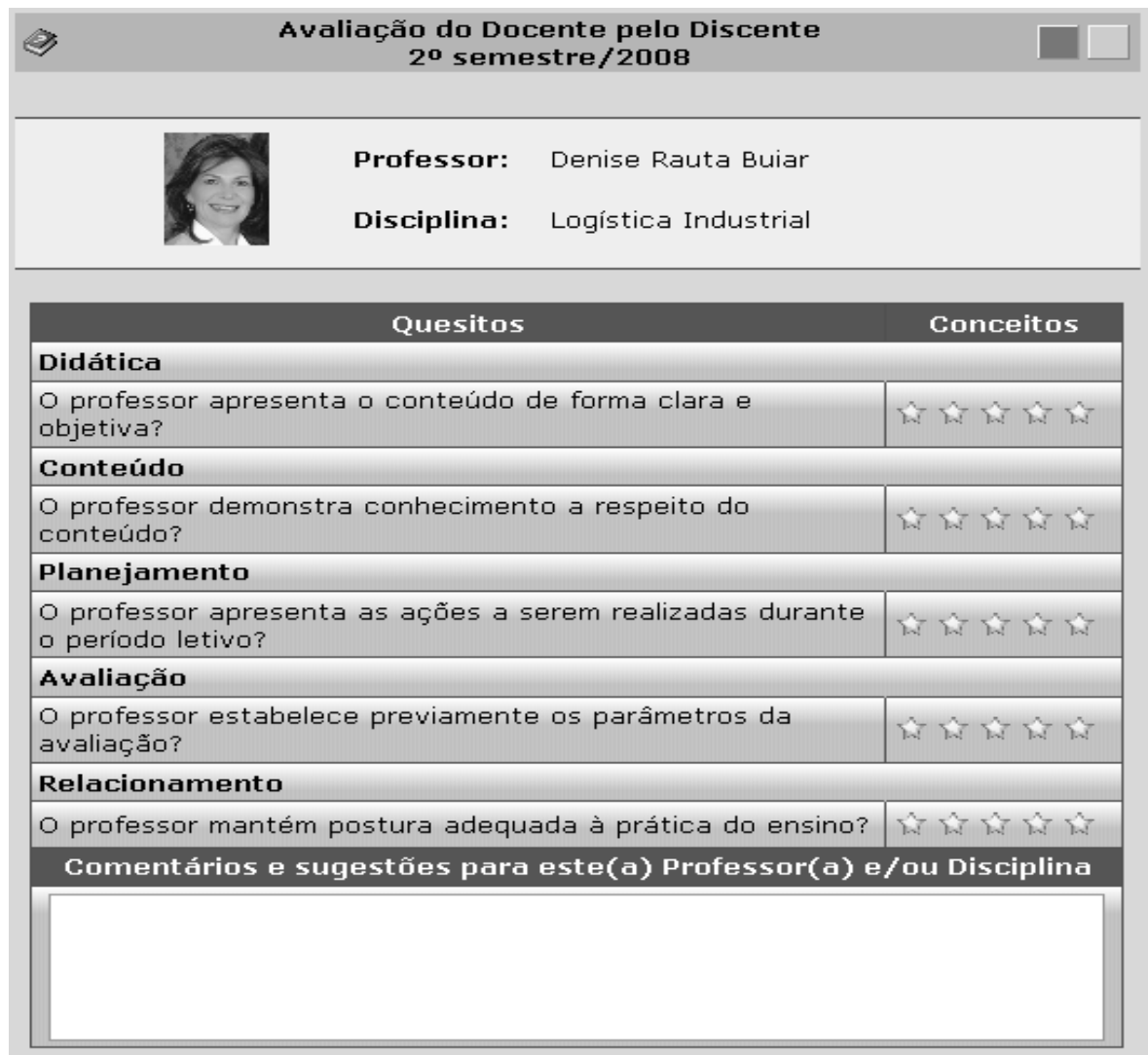

Fonte: UTFPR, (2009).

Uma vez finalizado o processo das avaliações do docente pelo discente, previsto em calendário acadêmico, o sistema gera dados estatísticos de cada um dos 14 departamentos acadêmicos do campus Curitiba, 19 coordenações, 27 cursos, mais de 700 professores e 1.000 disciplinas, que permitem aos chefes de departamentos, coordenadores de cursos e da área pedagógica de cada curso avaliar os itens do questionário.

Vale lembrar que os chefes, pedagogos e os coordenadores dos cursos podem acompanhar, na rede, a evolução do processo da avaliação do docente pelo discente diariamente, observando os que foram ou ainda não foram avaliados. Uma planilha 
nominada "ranking" permite visualizar o andamento da avaliação dos cursos que mais foram visitados e os que estão com baixo índice de participação dos alunos.

Esse processo proporciona aos alunos uma participação efetiva na busca pela melhoria da qualidade do ensino da Instituição, e orienta os professores nas possíveis correções de posturas, atitudes e comportamentos que conduzam, com equilíbrio, 0 desenvolvimento de suas práticas didático-pedagógicas. A relevância desta etapa da avaliação pode ser mensurada nas proporções presentes na totalidade dela. A UTFPR avalia o docente do seguinte modo: $30 \%$ da média referem- se à avaliação do docente pelo discente e $70 \%$ correspondem à produção de conhecimento individual e institucional. Os resultados finais repercutem na progressão funcional.

0 processo de avaliação do docente pelo discente ocorre em dois momentos: no primeiro semestre, e outro, no segundo semestre de cada ano letivo. Nele participam os alunos regularmente matriculados nos cursos da Educação Técnica Profissional, do Ensino Superior, da Educação de Jovens e Adultos. A seguir, são apresentados os índices de participação dos alunos da UTFPR nos últimos quatro anos.

A Figura 8 apresenta os percentuais de participação dos alunos no processo de avaliação do docente pelo discente. É importante ressaltar que os processos anteriores a 2009 eram parcialmente informatizados e não geravam relatórios. Foi somente no ano de 2009 que uma plataforma eletrônica de avaliação - plataforma do Sistema de Avaliação Institucional - SIAVI - foi elaborada com um número reduzido de questões se comparada com as anteriores, as quais continham 15 questões. Porém, os dados não revelam um aumento de participação em função das novidades. Percebe-se que as alterações na apresentação e no leiaute das telas não trouxeram mudanças significativas nas médias de participação. A UTFPR, todavia, pretende, contando com a colaboração dos professores, atingir maiores índices nas próximas avaliações. 
Figura 8 - Tela de avaliação do docente.

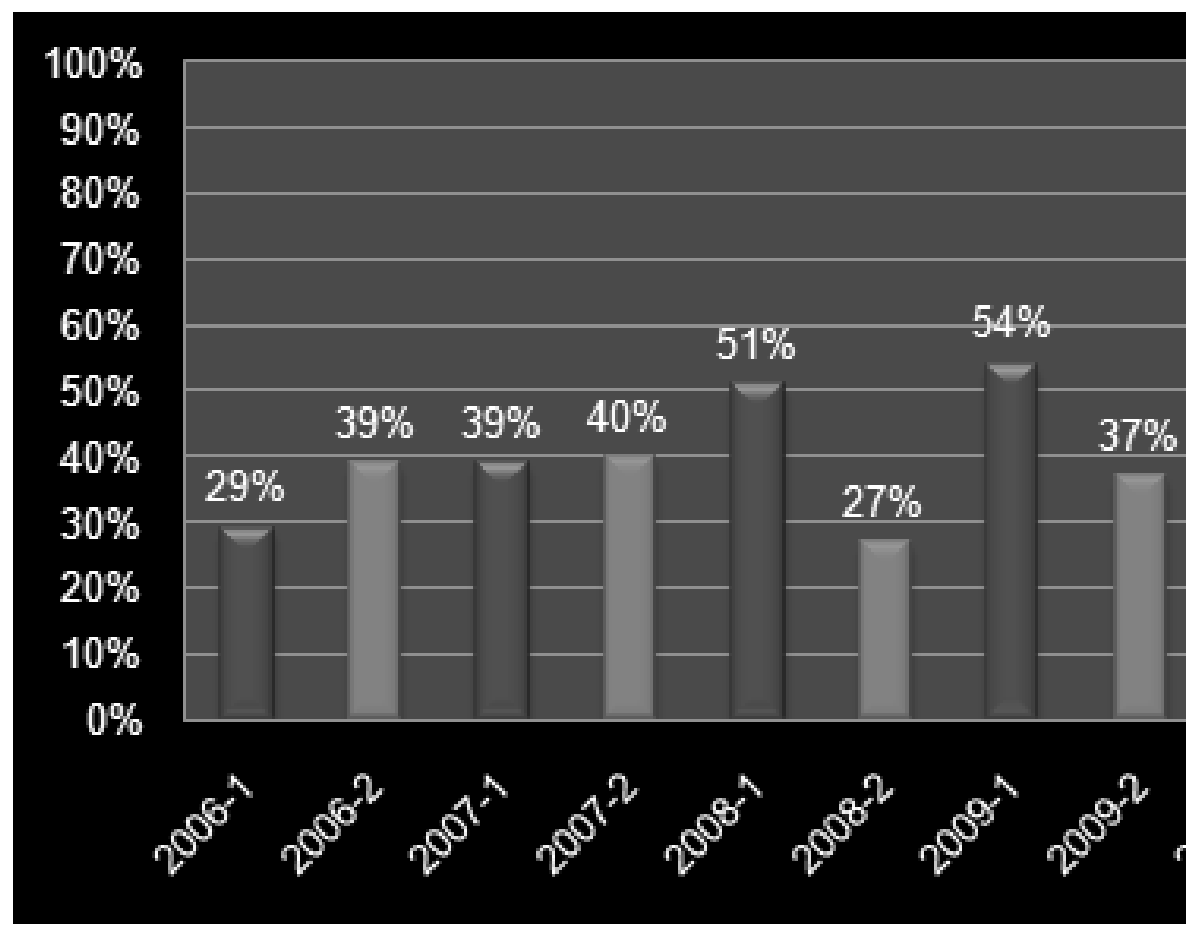

Fonte: UTFPR, (2009).

Desdobrando as informações da Figura 8, as Figuras 9 e 10 apresentam a escala de cursos e os índices de participação dos alunos na avaliação dos docentes. É possível acompanhar a evolução das avaliações on-line por curso, e os professores interessados, podem acessar as informações sobre as avaliações de suas disciplinas. 0 acompanhamento do "ranking" geral dos cursos, respectivamente do primeiro e segundo semestre revelaram maior número de avaliações nos cursos de Engenharia da Computação e de Design (19), e Sistemas de Informação e Física (2). Duas possíveis razões para este comportamento podem ser inferidas: a amicabilidade dos alunos com a máquina, e a divulgação pelos representantes da Comissão de Avaliação do Docente pelo Discente. 
Figura 9 - Tela de índice de participação dos alunos por curso do 1ํㅗ semestre de 2009.

\section{Ranking dos Cursos - Curitiba - $1^{\circ}$ Semestre de 2009}

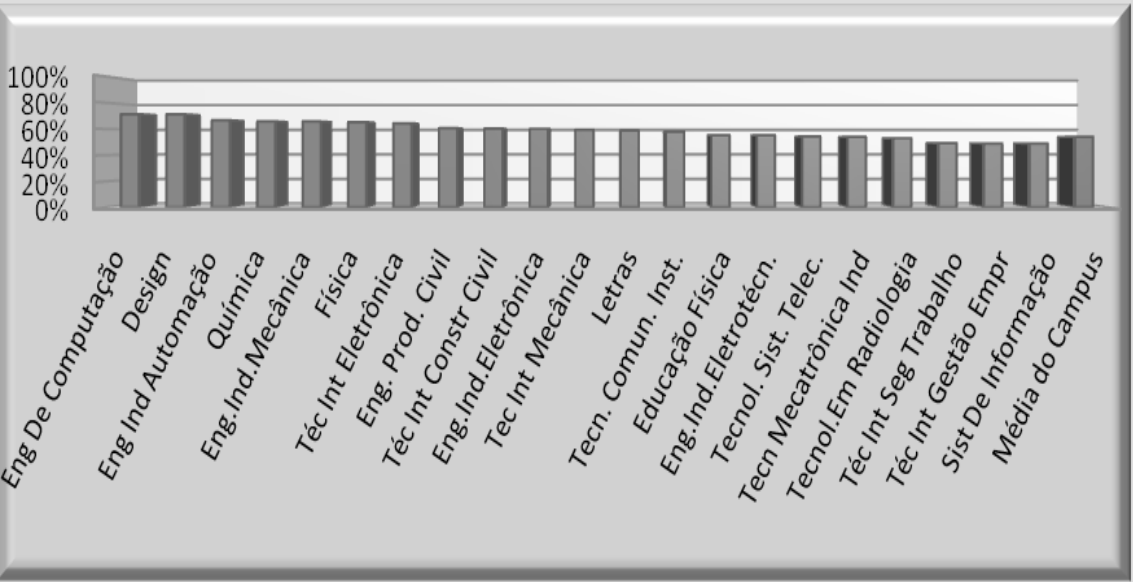

Fonte: UTFPR, (2009).

Figura 10 - Tela de índice de participação dos alunos por curso do 2ํsemestre de 2009.

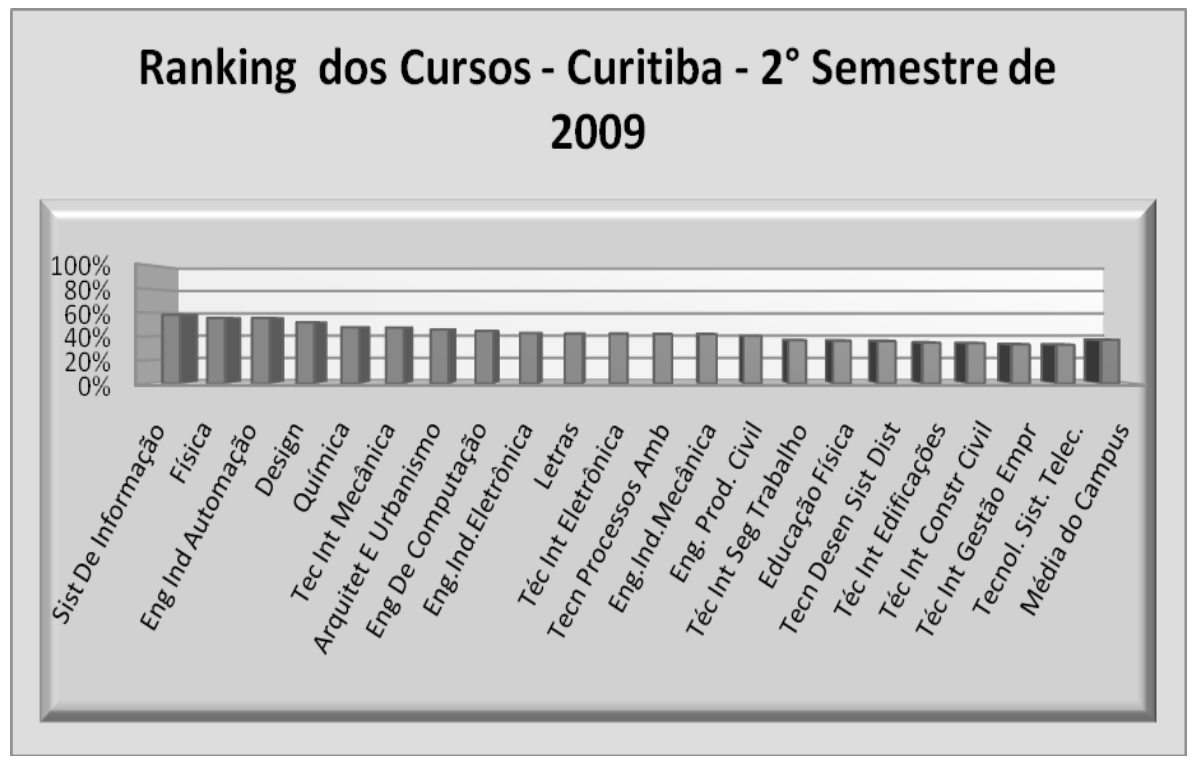

Fonte: UTFPR, (2009). 
Para realizar a atividade avaliativa, além da Comissão acima mencionada, a cada ano é constituída uma subcomissão representada por um professor de cada Departamento Acadêmico do Campus Curitiba. Eles trabalham no processo de sensibilização e acompanhamento do processo avaliativo junto aos chefes, coordenadores. Constitui-se em linhas gerais, da elaboração de cronograma de trabalho para realizar as ações do primeiro e segundo semestres do ano letivo e da divulgação visando a atingir percentuais significativos de participação dos alunos avaliando em todos os cursos oferecidos pela Instituição.

\section{Considerações finais}

A importância da participação dos discentes na avaliação está centrada na busca pela melhoria do ensino e da educação superior brasileira. 0 processo de avaliação do docente pelo discente da Universidade Tecnológica Federal do Paraná - UTFPR do Campus Curitiba, plataforma do Sistema de Avaliação Institucional - SIAVI - a cada ano vem apresentado evolução significativa de melhorias no processo, contando com 0 apoio dos recursos "midiáticos" disponíveis nas redes de web. Esse vem sendo caracterizado pelo bom desempenho, funcionamento e dedicação de profissionais na realização dos processos de avaliação na instituição.

As tendências de crescimento da participação dos discentes na avaliação vêm apresentando índices anuais pouco significativos, apesar das facilidades encontradas na aplicação de técnicas e tecnologias. Há que se contar sempre com um trabalho de sensibilização, necessário para o sucesso, que propicie melhoria nos índices de participação. Este empenho institucional para aumentar os dados avaliativos está vinculado também aos objetivos e à missão educacional, o qual pode, por meio das coordenações de cursos, fazer diagnósticos mais apurados, e mais rapidamente introduzir melhorias no processo de ensino aprendizagem.

O novo sistema de avaliação - plataforma do Sistema de Avaliação Institucional - SIAVI - com cinco questões contribui para agilizar o tempo dispensado para essa atividade e aborda questões relevantes no desempenho das funções do professor. Porém, é necessário que haja sempre uma reciclagem das abordagens das perguntas, introduzindo novas ideias de colaboração, de interdisciplinaridade, de contextualização socioeconômica e de aperfeiçoamento.

A UTFPR ainda encontra dificuldades para promover um aumento da motivação dos alunos para interagir com os professores e com a instituição por meio da avaliação do docente pelo discente. 0 processo didático-pedagógico é eternamente flexível e necessita de "alimentos" diferenciados para transformar e acrescentar novos resultados. Um fator muito pertinente nestes atos é o grau de comprometimento e envolvimento das pessoas na consecução de suas tarefas, na criação de ambientes propícios ao aprendizado, na discussão de conceitos, def inições 
e nos relacionamentos. A individualidade, a formação pessoal e/ou pregressa dos acadêmicos marcam as potencialidades humanas para compartilhar as ideias e experiências democráticas, de cidadania nas práticas cotidianas escolares.

$\mathrm{Na}$ aprendizagem includente, considerando as diferenças e os diferentes, as atividades canalizam o desenvolvimento de capacidades critico-reflexivas alinhadas à reconstrução. A questão da avaliação complementa este processo no momento da tomada de decisões, com os diagnósticos que permitem a análise de dados representativos nas distintas áreas de conhecimento.

0 aluno que tem acesso à plataforma do Sistema de Avaliação Institucional SIAVI - realiza a avaliação de seu professor segundo sua concepção momentânea, consciente da importância da sua participação no processo de avaliação. Mas, ele precisa ser responsável sobre seu grau de dedicação e comprometimento com 0 curso, a atenção, a disciplina, e a freqüência. Seria ideal para a Instituição realizar avaliações bimestrais e antes e depois do trancamento de matricula para coletar amostras mais significativas e mais apuradas.

\section{Referências}

BERTELLI, E. M. Avaliação institucional: a trajetória da faculdade de Pato Branco. 2004. Dissertação (Mestrado)- Programa de Pós- Graduação em Educação, Pontifícia Universidade Católica do Paraná, Curitiba, 2004.

BRASIL. Constituição (1988). Constituição da República Federativa do Brasil. Brasília, DF: Senado Federal, 1988.

. Decreto n. 02.026 , de 10 de outubro de 1996. Estabelece procedimentos para o processo de avaliação dos cursos e instituições de ensino superior. Diário Oficial [da] República Federativa Brasil, Brasília, DF, 11 out. 1996a. Seção 1, p. 20545.

Lei $\mathrm{n} 010.861$ de 14 de abril de 2004. Institui o Sistema Nacional de Avaliação da Educação Superior e dá outras providências. Diário Oficial [da] República Federativa Brasil, Brasília, DF, 15 abr. 2004. Seção 1, p. 3- 4.

CADPD. COMISSÃO DE AVALIAÇÃO PERMANENTE DO DOCENTE PELO DISCENTE. Fluxo do processo de avaliação do docente pelo discente. Universidade Tecnológica Federal do Paraná. Curitiba: Editora da UTFPR, 2009.

ADPD. Avaliação do docente pelo discente. Universidade Tecnológica Federal do Paraná. Curitiba: Editora da UTFPR, 2009. 
EYNG, A. M. A avaliação como estratégia na construção da identidade institucional. Revista da rede de avaliação institucional da Educação Superior, Campinas, v. 9, n. 3, p. 31-50, set. 2004.

IBARROLA, M. Experiências y reflexiones sobre el diseño y la evaluación curricular. In: CONGRESO EDUCATIVO INTERNACIONAL EVALUACIÓN, 6., 2008, M éxico. Anais... México: RedEtis, 2008.

INEP. Instituto Nacional de Estudos e Pesquisas Educacionais Anísio Teixeira. Página Oficial. Brasília, DF: INEP, 2010. Disponível em: <http//:www.inep.gov.br>. Acesso em: 08 ago. 2010.

KLOSOUSKI, S. S.; REALI, K. M. Planejamento de ensino como ferramenta básica do processo ensino-aprendizagem. Revista Eletrônica Lato Sensu, Paraná, 2008. Disponível em: <http://www.horacio.pro.br/fmp/2012-1/planejamento/7-Ed5_CHPlane.pdf >. Acesso em: 07 fev. 2013.

MARTIN, D. F. A aprendizagem em Paulo Freire e Piaget. 2007. Trabalho de Conclusão de Curso (Graduação em Pedagogia)-Escola de Pedagogia, Universidade Estadual Paulista, Bauru, 2007. Disponível em: < http://www.fc.unesp.br/upload/pedagogia/ TCC\%20Daniele\%20-\%20Final.pdf>. Acesso em: 06 fev. 2013.

M ORAES, S. A. de; TERUYA, T. K. Paulo Freire e formação do professor na sociedade tecnológica. [Paraná: Unioeste, 2010]. Disponível em: < http://www.unioeste.br/ cursos/cascavel/pedagogia/eventos/2007/Simp\% C3\%B3sio\%20Academico\% 20 2007/Trabalhos\%20Completos/Trabalhos/PDF/64\%20Sonia\%20Algusta\%20de\%20 Moraes.pdf >. Acesso em: 11 mai. 2010.

PRIETO, C. Implicación, impacto y utilidad de metodologías participativas en la evalución: un estudio de caso en la evaluación del aprendizaje universitario. 2009. $40 \mathrm{f}$. Tese (Doutorado)-M emorial del proyecto de tesis doctoral, 2009.

SANTOS, V. P. dos. 0 que fazer na sala de aula: didática, metodologia ou nada disso?. Dialogia, São Paulo, v. 2, out. 2003. Disponível em: <http://www.unibarretos.edu. br/v3/faculdade/imagens/nucleo- apoio-docente/pesquisa\%20sala\%20de\%20aula6. pdf >. Acesso em: 06 fev. 2013.

SINAES. Sistema Nacional de Avaliação da Educação Superior. Bases para uma nova proposta de avaliação da educação superior. Brasília, DF: SINAES, 2003. Disponível em: <http://portal.mec.gov.br/arquivos/pdf/sinaes.pdf>. Acesso em: 24 set. 2011. 
STUFFLEBEAM, D. The CIPP Model for program evaluation. In: MADAUS, G. F.; SCRIVEN, M. S.; STUFFLEBEAM, D. L. (Orgs.), Evaluation models: viewpoints on educational and human service evaluation. Boston: Kluwer-Nijhoff, 1983. p.117-142.

STUFFLEBEAM, D.; SHINKFIELD, A. Evaluación sistemática: guia teórica y práctica: Centro de Publicaciones del Ministério de Educación y Ciência. Espanha: Ediciones Paidós, Ibérica. 1995.

VARGAS, A. I. M. La evaluación educativa: concepto, períodos y modelos. Revista electrónica actualidades investigativas em educación, San José, Costa Rica, v. 4, n. 2, p. 1-28, jul./dic. 2004. Disponível em: < http://revista.inie.ucr.ac.cr/uploads/ tx_magazine/periodos.pdf >. Acesso em: 10 abr. 2010.

VASCONCELOS, A. A. de et al. A presença do diálogo na relação professor-aluno. In: COLÓQUIO INTERNACIONAL PAULO FREIRE, 5., 2005, Recife. Anais eletrônicos... Recife: Centro Paulo Freire - estudos e pesquisas, 2005. Disponível em: < http:// www.paulofreire.org.br/pdf/comunicacoes_orais >. Acesso em: 06 fev. 2013.

VIANNA, H. M. Introdução à avaliação educacional. São Paulo: Ibrasa, 1989.

UTFPR. UNIVERSIDADE TECNOLOGICA FEDERAL DO PARANÁ. Portal do aluno. Disponível em: <http://www.ct.aluno.utfpr.edu.br>. Acesso em: 06 Mai. 2010.

Recebido em: 23/09/2010

Aceito para publicação em: 17/01/2013 